\title{
Aggregate Index of Sustainable Development of Mining Regions in Siberian Federal District
}

\author{
Yevgenya Senchenko, and Yelena Fakhrislamova, ${ }^{2}$, \\ ${ }^{1}$ Novosibirsk State Technical University, 630073 20, Prospekt K. Marksa, Novosibirsk, Russia \\ ${ }^{2}$ Plekhanov Russian University of Economics, 650992, Kuznetskiy Prospect, 39. Kemerovo, Russia
}

\begin{abstract}
Currently, governments of both developed and developing countries are interested in forming an adequate analytical tool for assessing the effectiveness of measures taken for the transition to sustainable development. These tools should take into account the dualism of sustainable development, in which the acceleration of economic growth, inspired by scientific and technological progress, should be correlated with a decrease in the negative anthropogenic impact on the environment. In this regard, widespread methods for assessing the prospects for the transition to sustainable development is the calculation of indices that aggregate the dynamics of socio-economic and environmental processes at the global, national and regional levels. This article identifies mining regions of Siberian Federal District as an object, the assessment of which is carried out on the basis of the Governmental methodology of Russian Federation, adapted to the objectives of the study of the prospects for the transition to sustainable development. The result of the study is the ranking of mining regions of the Siberian Federal District on the integral index of sustainable development and the defining the dominant trend.
\end{abstract}

\section{Introduction}

In world practice, there is a tendency to the formation of indices reflecting the social, economic, environmental and other elements of sustainable development as a complex phenomena. At the same time, the methodological support of their construction depends on the priority directions of the development of the country and the interrelations revealed in a certain time period.

It is important to note that several methods of assessing the environmental and socioeconomic development of the region are considered in Russian Federation. So Girina A.N. as the evaluation criteria highlights the target differences of the main existing methods [1]:

1. Determination of the degree of additional financing of the environmental measures in the region (Governmental methodology).

2. Formation of an indicator of interregional differentiation of social, economic and ecological progress.

3. Elimination of unevenness in the levels of socio-economic development and environment

\footnotetext{
${ }^{*}$ Corresponding author: elena.fah@yandex.ru
} 
problems of the regions.

4. Characteristic of the management efficiency of the socio-economic and ecological development of the region.

5. Analysis and forecasting of the socio-economic and ecological development of regions (Institute of Economy of Russian Academy of Science).

Thus, summarizing the abovementioned point one can speak about the current methodologies flexibility irrespective of its author's center of concerns.

The Russian Federation has regions and federal districts differentiation. It is conditioned by the number of the following factors: climatic and natural conditions, territorial remoteness from the center, environmental situation, business activities, etc. In this context, it is advisable to apply this particular methodology within the framework of a certain federal district.

The current Russian program of sustainable development justifies the aim of the present research. The authors made the attempts to assess the trend of sustainable development transition in the regions of Siberian Federal District which specialized on mineral resources mining by highlighting comparable criteria within available temporary periods. Based on Federal State Statistics Service [2] the essential index calculations were made using the adapted Government methodology and the available official information. [3].

\section{Materials and Methods}

The purpose of the study was to assess the socio-economic situation of the regions of Siberian Federal District based on the application of the Governmental methodology and the introduction of certain indicators into the assessment.

To achieve this goal, the following main tasks were solved:

- assessment of the main indicators of the socio-economic development of regions put forward by the Government of the Russian Federation;

- as an additional criteria to assess the problems of the transition to sustainable development like atmospheric emissions, thous. tons.

The object of research is the socio-economic characteristics of the regions of the Siberian Federal District.

The index is a relative characteristic of the change in the cumulative phenomenon in the current period compared with the previous one (chain index). Index values are in the range from 0 to 1 and are expressed by coefficients (times). Thus, by data ranging per annum in the frame of regions the maximum $\left(X_{\min i}\right)$ and minimum $\left(X_{\min i}\right)$ values are applied in the (1).

$$
I=\frac{X_{i}-X_{\min i}}{X_{\max i}-X_{\min i}}
$$

But it is necessary to distinguish the role of each above-mentioned indicator. As to the general economic and environmental development aggregated by (1) the individual indexes of a reverse nature $\left(I_{h}\right)$ were calculated using (2).

$$
I_{h}=1-\frac{X_{i}-X_{\min i}}{X_{\max i}-X_{\min i}}
$$

Intermediate calculations were performed using Microsoft Excel. The results were obtained in the form of summary tables, figures and their analysis. Specify that all values are obtained by the authors in the process of calculations.

\section{Results and Discussion}

All the calculated indexes are presented as a multiple, and they were converted in percentage terms. Gross Regional Product (GRP) assessment per capita within annual current prices was 
made on the basis of traditional statistical analysis methods (Fig. 1).

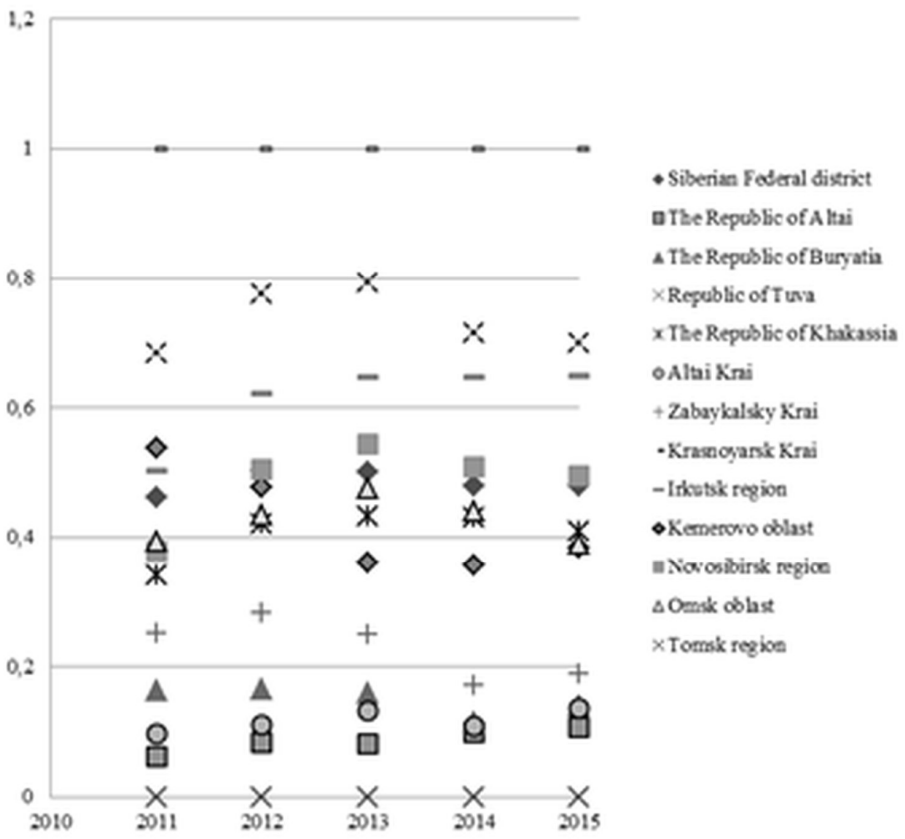

Fig.1. GRP's Integral Index per Capita, the Siberian Federal District regions (as a multiple).

The calculation results of GRP integral index per capita for five years (Fig. 1) indentified Tuva Republic as the anti-leader which and Krasnoyarsk Krai (Krasnoyarsk Territory) as the leader. The calculation of industrial production index dynamics (by 2011 with the progressive total was applied) is presented on Fig. 2.

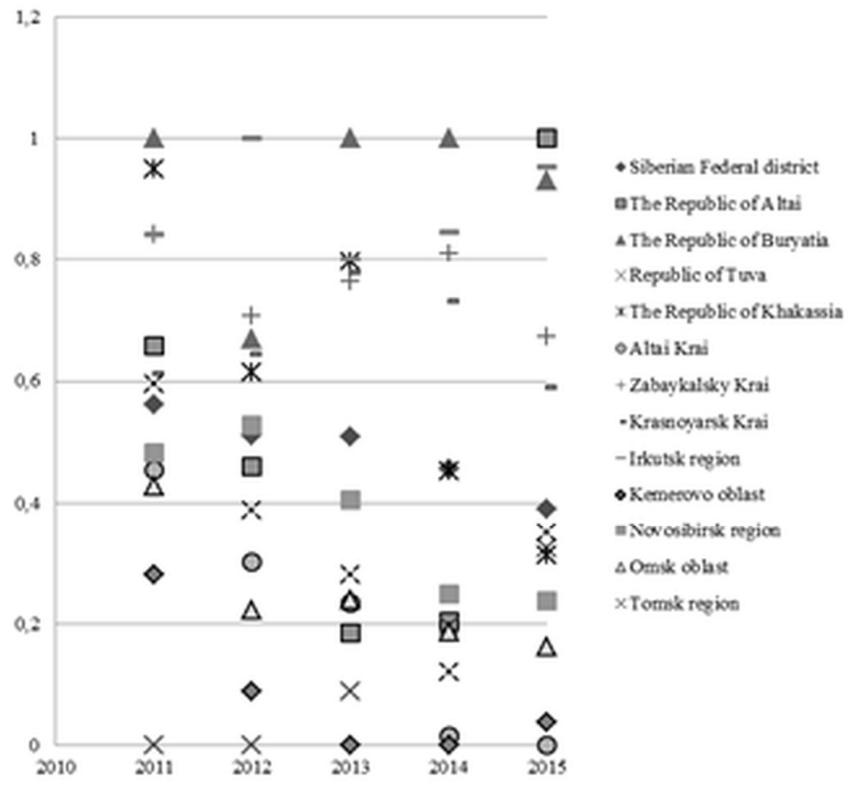

Fig. 2. Integral Index of Industrial Production of Siberian Federal District regions (by 2001 with the progressive total was applied, (as a multiple). 
Fig. 2 data need to be clarified: dynamics calculation was made through the chain index converting to the basic one, as an example, the 2015 value is the result of the industrial production chain index product for five years. In 2015 the critical values were received by the Republic of Altai - maximum, and Altai Krai - minimum. Specifying the investments volume per capita in million Russian rubles, the following results are obtained (Figure 3).

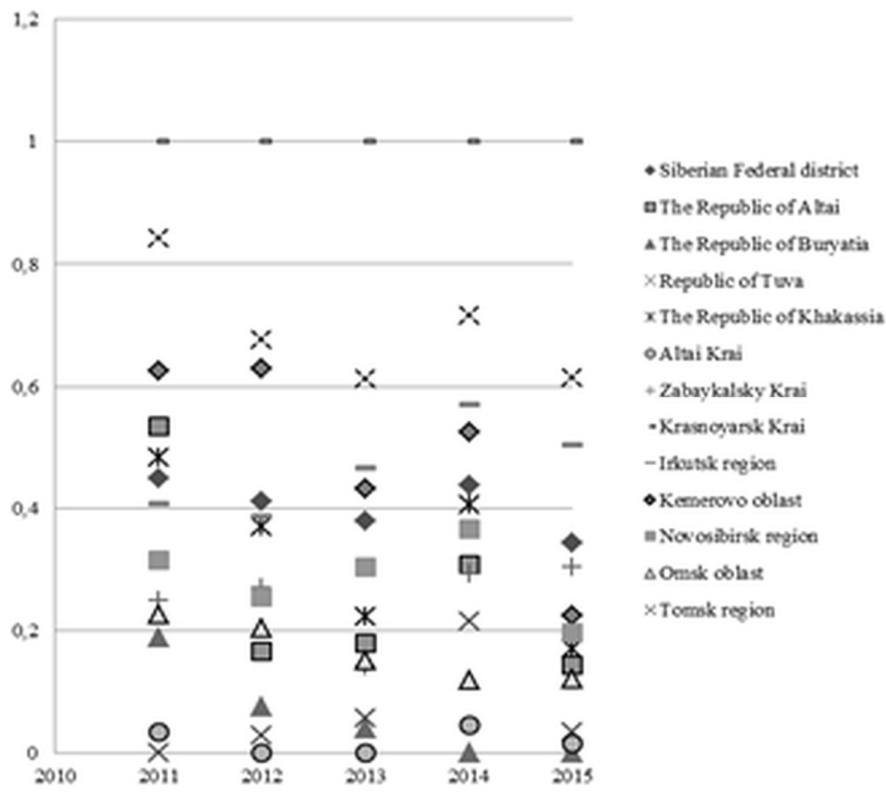

Fig. 3. Integral Index of investments volume per capita in Siberian Federal District regions, in multiple.

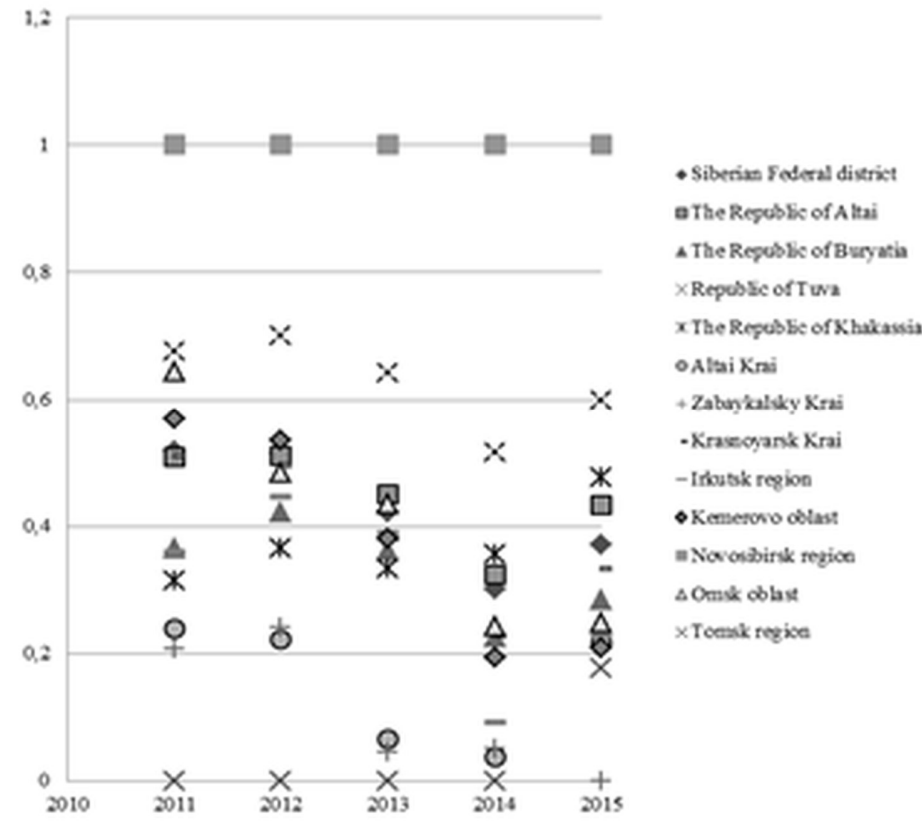

Fig. 4. Integral Index of Residential Buildings Commissioning per 1000 Persons of Population in the Siberian Federal District regions, in multiple. 
The Fig. 3 obtained results allow to make a conclusion: Krasnoyarsk Krai within the complete period of analysis is the leader in mobilization of the investment per capita in Siberian Federal District regions at large. It should be noted that by 2015 Zabaykalsky Krai and Irkutsk Oblast improved their status due to the regional redistribution. The rest regions have the lagging behind tendency. As an example, Kemerovo oblast decreased by $40.1 \%$.

Residential buildings commissioning analysis per 1000 heads of the population (living space, $\mathrm{m}^{2}$ ) is presented on Fig. 4 .

The clear front-runner in the construction sector is becoming Novosibirsk Region. Other regions mainly have index values less than 50\%, Moreover, they have the decreasing tendency against benchmarking.

The ecological factor was assessed through the volume of pollutants discharge into open air from the stationery pollution sources per capita (Fig. 5). In the rating, the absolute value increase should result in aggregate index decreasing. The range of variation made in 0.828 thousand tons of pollutants per capita.

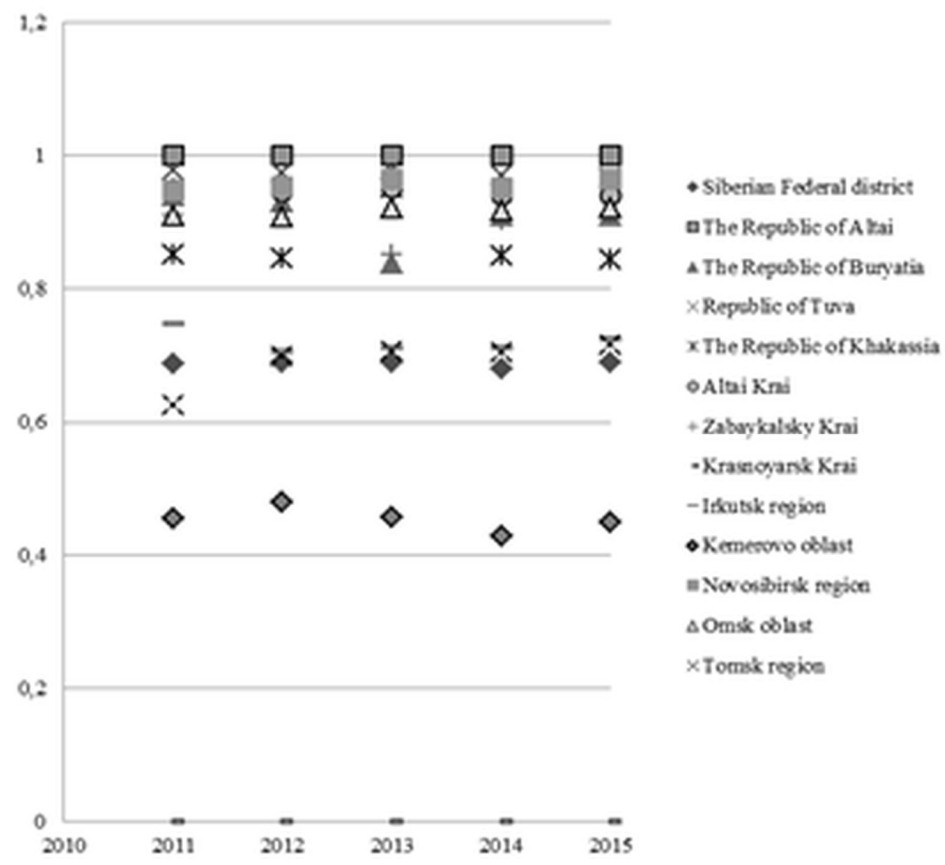

Fig. 5. Aggregate Index of Pollutants Discharge into Open Air from Stationery Pollution Sources in SFD Regions, in multiple.

Fig. 5 data characterize Kemerovo oblast as the most polluted area, the second position was taken by Tomsk oblast with the advantage of approximately $20 \%$.

Total results of sustainable development indexing in Siberian Federal District regions are presented in the curve (Fig. 6). 


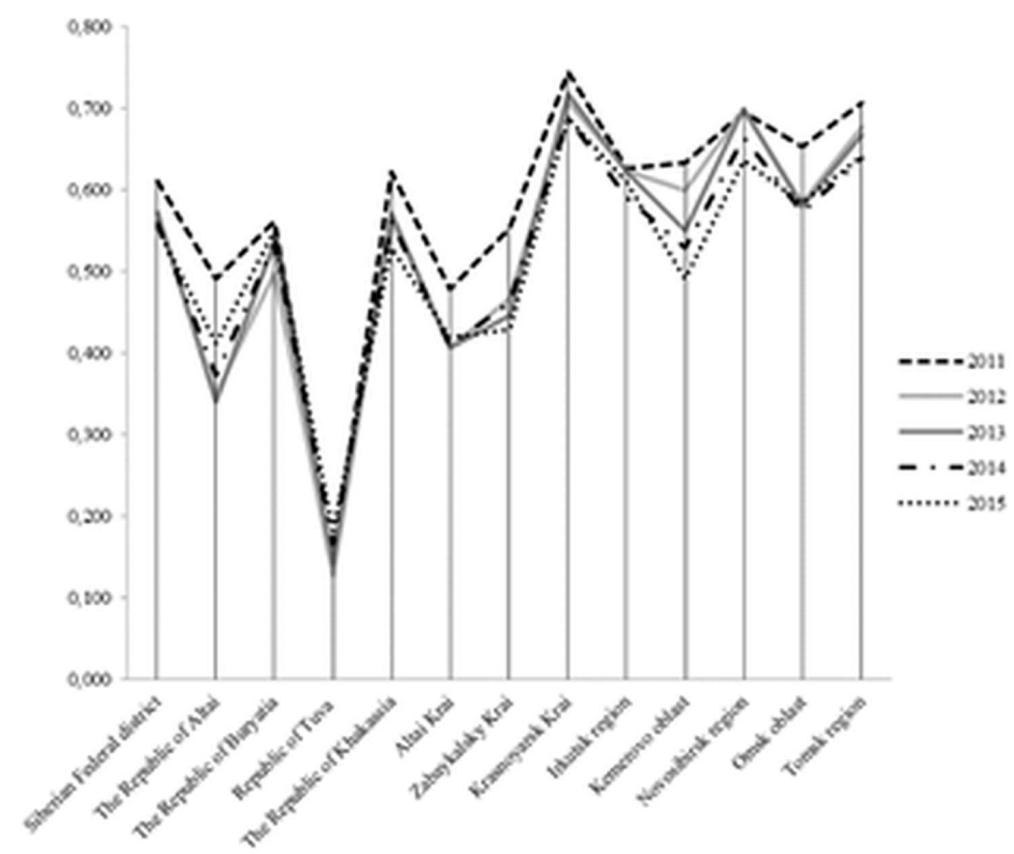

Fig. 6. Aggregate Index of sustainable development of Siberian Federal District regions.

On the whole, the analysis made is characterized by little deviations in the region development dynamics. For five years the first leader has become Krasnoyarsk Krai. The survey results are reliable as official statistics data were used as the initial base.

\section{Conclusion}

An important element of forming strategies for the transition of regions to sustainable development, making management decisions at the level of regional administrations is the analysis of the relationship of the development of economic and environmental activity in the region. The results of the analysis lead to the conclusion about the effectiveness of the measures of state support provided. An assessment of the prospects for the sustainable development of the regions of the Siberian Federal District suggests a conclusion: the Tyva Republic has a clear drop from the development of the neighboring regions, despite some attempts to improve environmental situation. In the analyzed five-year period, there were no significant changes in the republic. Leaders in the transition to sustainable development in the Siberian Federal District are Krasnoyarsk region, Novosibirsk and Tomsk regions.

\section{References}

1. A.N. Girina, Bulletin of the OSU, 8:157, 82-87 (2013)

2. Regions of Russia. Socio-economic indicators (Rosstat, Moscow, 2016)

3. Methodology for a comprehensive assessment of the level of social and economic development of the constituent entities of the Russian Federation (Rosstat, Moscow, 2018) 